\title{
Principles, Approaches, and Methods for Evaluation in Indigenous Contexts: A Grey Literature Scoping
} Review

\author{
Kriti Chandna, Michelle M. Vine, Susan J. Snelling, and Rachel Harris \\ Public Health Ontario \\ Janet Smylie and Heather Manson \\ University of Toronto
}

\begin{abstract}
This article describes findings from a scoping review of the grey literature to identify principles, approaches, methods, tools, and frameworks for conducting program evaluation in Indigenous contexts, reported from 2000-2015 in Canada, the United States, New Zealand, and Australia. It includes consultation with key informants to validate and enrich interpretation of findings. The fifteen guiding principles, and the approaches, methods, tools, and frameworks identified through this review may be used as a starting point for evaluators and communities to initiate discussion about how to conduct their evaluation in their communities, and which approaches, methods, tools, or frameworks would be contextually appropriate.
\end{abstract}

Keywords: evaluation, Indigenous communities, Indigenous context, scoping literature review

Resumé : L'article décrit les résultats d'une revue exploratoire de la littérature grise pour cerner les principes, les approches, les méthodes, les outils et les cadres d'application liée à la réalisation dévaluations de programme dans des contextes autochtones, qui ont fait l'objet de rapports de 2000 à 2015 au Canada, aux ÉtatsUnis, en Nouvelle-Zélande et en Australie. Des intervenants clés ont été consultés pour valider et enrichir l'interprétation des résultats. Les 15 principes directeurs, ainsi que les approches, les méthodes, les outils et les cadres d'application découlant de cette étude peuvent servir de point de départ pour les évaluateurs et les communautés afin de discuter des approches, des méthodes, des outils ou des cadres les plus appropriés à leur contexte particulier.

Mots clés : évaluation, communautés autochtones, contexte autochtone, revue exploratoire de la littérature

Corresponding author: Michelle Vine, Department of Health Promotion, Chronic Disease and Injury Prevention, Public Health Ontario, Suite 300 - 480 University Avenue, Toronto, ON M5G 1V2; michelle.vine@oahpp.ca 
Evaluation of Indigenous health programs and services is recognized as a fundamental component of public health practice in Canada (Public Health Agency of Canada [PHAC], 2015). Evaluations can contribute to improving program planning and delivery, determining the effectiveness and impact of programs, demonstrating accountability to communities and funders, and informing program decisions (Rossi, Lipsey, \& Freeman, 2003; Zorzi, Perrin, Mcguire, Long, \& Lee, 2002).

Having endured a long history of exploitation in research contexts, many Indigenous peoples are skeptical of researchers and evaluators (Castellano, 2004). External evaluators have imposed and conducted evaluations on Indigenous communities (LaFrance \& Nichols, 2008; Smith, 1999; Taylor, 2003). This has been exacerbated by substandard practices in designing and implementing evaluations, a lack of resources available for conducting Indigenous evaluations (Chouinard \& Cousins, 2007), inadequate population health data (Smylie \& Anderson, 2006), and incongruent expectations between community and evaluators related to evaluation in Indigenous contexts (Grover, 2010). There is growing recognition that these evaluations are embedded in unique social and historical contexts and must be conducted in culturally relevant and meaningful ways (Chouinard \& Cousins, 2007; National Aboriginal Health Organization, 2003). Ultimately, these practices are fundamental for reconciliation between Indigenous and non-Indigenous peoples in Canada (Truth and Reconciliation Commission [TRC], 2015).

\section{CONTEXT}

This scoping review was initiated to identify wise practices for undertaking evaluation in Indigenous contexts after co-author Dr. Heather Manson (Public Health Ontario) was asked to evaluate a government-funded health-promotion program (the Healthy Kids Community Challenge), implemented in six Indigenous and thirty-nine non-Indigenous communities across Ontario. Dr. Manson established a partnership with Dr. Janet Smylie of the Well Living House Action Research Centre for Indigenous Infant, Child and Family Health and Wellbeing, and invited Dr. Smylie to sit on the Scientific Reference Committee of the Healthy Kids Community Challenge, and chair its Aboriginal Stream Scientific Subcommittee (ASSSC). The team conducted this scoping review with the guidance of Dr. Smylie, a Métis scholar with over 20 years of experience in Indigenous research and evaluation. We also engaged key informants throughout this process; they included experts from local, provincial, and national Indigenous organizations, and academics in the field of Indigenous health research and evaluation. Recognizing this team's diverse backgrounds and varied experiences in conducting evaluations in Indigenous contexts, we undertook this scoping review with a commitment to critical self-reflection and learning. This article reports on findings of the scoping review, including the key informant consultations. 


\section{OBJECTIVES}

The objectives of this review were to

1. conduct a scoping review of the grey literature ${ }^{1}$ to identify principles, approaches, methods, tools, and frameworks reported in Indigenous health service or program evaluation contexts in Canada, the United States, New Zealand, and Australia; and,

2. consult with key informants to identify gaps in knowledge and understanding, and validate and enrich interpretation of the preliminary findings.

\section{METHODS}

This scoping review follows methodology established by Arksey and O'Malley (2005), and adapted by Levac, Colquhoun, and O'Brien (2010). Unlike systematic reviews, which answer focused questions from quality assessed studies, scoping reviews aim to capture breadth and describe characteristics of literature in complex and understudied research areas (Arksey \& O'Malley, 2005; Levac et al., 2010). Given that the topic of evaluation in Indigenous contexts fits this description, we chose scoping review methodology to characterize literature in this area. By systematically "mapping" the literature in tabular form (Pham et al., 2014), scoping reviews provide readers with an overview of existing literature to identify areas where further research may be required; however, they do not evaluate the quality or depth of literature (Arksey \& O'Malley, 2005). This distinction is important in the current context, as this review intended to understand what has been reported in the literature rather than making quality assessments or value judgments.

This scoping review of grey literature complements a systematic review of peer-reviewed literature led by co-author Smylie and colleagues at the Well Living House on a similar topic (Maddox et al., in press).

\section{Stage 1: Identifying the research question}

This scoping review was guided by the following research questions and corresponding objectives:

1. What principles for research or evaluation have been reported in Indigenous contexts?

a. To identify and document guiding principles for research or evaluation in Indigenous contexts, including governance and management of health information;

2. What approaches, methods, tools, and frameworks have been used in Indigenous health service or health program evaluation in Canada, the United States, Australia, and New Zealand? 
a. To undertake a scoping review of grey literature to identify and describe evaluation approaches, methods, tools, and frameworks from Indigenous health-service and health-program evaluation contexts; and

b. To validate the identified principles, approaches, methods, tools, and frameworks in evaluation practice, and to identify others, via consultation with key informants.

\section{Stage 2: Identifying relevant studies}

Google and Google Custom Engine searches were performed using a search strategy developed in consultation with two research librarians at Public Health Ontario (PHO). The Google Custom Search Engine was developed through an exploratory Google search, through which websites related to Indigenous health services or health programs were identified (e.g., National Collaborating Centre for Aboriginal Health, Health Promotion Forum of New Zealand, National Congress of American Indians Policy Research Center). An initial list was crossreferenced with a list of Indigenous organizations compiled by the Research Library at Athabasca University in Alberta, Canada (2015), and reviewed by a research librarian at $\mathrm{PHO}$ for completeness. Further, the research team e-mailed the initial list to key informants, requesting feedback via telephone or e-mail. At this stage, no additional websites were identified. Ninety-six websites were drawn upon to create the Google Custom Search Engine. Eight search queries, with terms such as "Indigenous," "Aboriginal," "health," "evaluation," and "evaluationresearch" were executed using both search engines between June 17 and 19, 2015. Search results included grey literature from both research and evaluation contexts, as well as literature from various sectors, including health, justice, and education.

Despite limitations in search-engine functionality (e.g., queries limited to 32 search terms), search terms and queries were designed to be comprehensive in order to capture the most relevant literature in the first 100 results of each search. Formal grey literature repositories were not searched since repositories were not expected to produce distinct results; search strategies would have needed to be developed for each repository; and time limitations would have made screening a high volume of results impractical.

\section{Stage 3: Study selection}

\section{Inclusion criteria}

The initial set of inclusion criteria was adapted from criteria developed by Smylie and colleagues as part of their systematic review (Maddox et al., in press). Two types of documents were included: guidance documents, which describe how to conduct evaluation in Indigenous contexts; and application documents, which describe the execution of evaluations in Indigenous contexts. When documents were identified that included principles related to research (and not necessarily evaluation only) in Indigenous contexts, these were also included. 
In general, English-language grey literature published from 2000-2015 was eligible for inclusion. Results that did not focus on Indigenous communities, or did not originate in Canada, the United States, Australia, or New Zealand, were excluded from this review. As Reading (2009) argues, research must work collaboratively with Indigenous communities and organizations around the world, and specifically in Australia, New Zealand, North America, and circumpolar and low-income nations, in order to resolve complex health issues and other legacies of colonization. Canada, Australia, New Zealand, and the United States were specifically included in this review because their Indigenous populations have faced similar histories of colonialism, systemic racism, social exclusion, geographic dislocation, and cultural persecution (Armitage, 1995; Reading, 2009; Reading \& Wien, 2009).

\section{Principles}

Principles were defined as "a fundamental truth or proposition that serves as the foundation for a system of belief or behaviour or for a chain of reasoning" ("Principle," n.d.). Explicit principles were named or referenced as a principle or principle set (e.g., OCAP Principles) in the literature, while implicit principles were those that emerged as such. To sensitize authors to implicit principles and develop data-charting categories, Smylie identified five exemplar articles describing principles for conducting research and evaluation in Indigenous communities. Drawing on the five documents (Chesterton, 2003; LaFrance \& Nichols, 2008; National Collaborating Centre for Aboriginal Health, 2013; Putt, 2013; Smylie, Lofters, Firestone, \& O'Campo, 2011), members of the research team $(N=4)$ identified emergent principle theme categories (PTC) by grouping quotations and examples identified throughout the documents. PTCs were refined through discussions within the team and consultation with the Well Living House team until consensus was reached (see Table 1).

As a validation step, the initial PTCs were reviewed in comparison with Chapter 9: Research involving the First Nations, Inuit, and Métis people of Canada of the Tri-Council Policy Statement (2nd ed.): Ethical Conduct for Research Involving Humans [TCPS II] (CIHR, NSERC, \& SSHRC, 2014). The TCPS II was adopted as a validation source given that it represents national standards by which all Canadian research must comply, it was written in partnership with Indigenous stakeholders, and it contains language intended for use in this area.

\section{Screening}

The first 100 results of each query were screened. After removing duplicate websites and published sources, we conducted a title and abstract screen, followed by a full text review. Where abstracts were not available, executive summaries or tables of contents were screened. Additionally, $20 \%$ of results were independently screened by a second reviewer at each step ( $n=193$ and $n=88$, respectively), with the goal of achieving consistency in more than $80 \%$ of inclusion decisions. In the event that more than $80 \%$ agreement was not reached, inclusion criteria were reviewed and the exercise was repeated until this threshold was reached. 
Table 1. The principle theme categories from most to least frequently cited

\section{No. Principle Theme Category}

1 Research with Indigenous communities uses community engagement - prior to the start of the research project, OR during the research project, OR after the data has been collected (i.e., during data analysis and interpretation, and during knowledge transfer and dissemination)

2 Research with Indigenous communities is culturally appropriate and culturally safe. It reflects, and is responsive to, cultural values

3 Research with the Indigenous community is specific to the community's context

4 Researchers demonstrate respect for participants and subjects

5 Researchers demonstrate core values, such as honesty, inclusion, integrity, openness, trust, etc.

6 Research efforts are relevant and responsive to community objectives

7 Research partnerships/collaborations help to facilitate local capacity building

8 The research is guided by community self-determination

9 The benefits of the research are greater than its risks; i.e., the research is beneficial for the community participating in the research

10 Research with Indigenous communities is grounded in Indigenous epistemologies (i.e., Indigenous ways of knowing)

11 Research demonstrates respect for Indigenous knowledge systems

12 Researchers demonstrate reciprocity for subjects and participants

13 Indigenous communities have a role with respect to data governance and management

14 Research involving Indigenous peoples must be reviewed and approved by an appropriate Research Ethics Committee

15 The research acknowledges power imbalances between Indigenous and nonIndigenous researchers

After reaching this agreement score, any disagreements were resolved through discussion until reviewers reached consensus.

\section{Snowballing}

Greenhalgh and Peacock (2005) advise snowballing ${ }^{2}$ as part of a multi-component strategy to identify key pieces of evidence where literature is "complex and heterogeneous" (p. 1065). In addition to Google and Google Custom Engine searches, we snowballed reference lists, as snowballing was a highly targeted activity for which a high yield was expected (Greenhalgh \& Peacock, 2005). Reference lists of included results were screened to identify additional grey literature that may have been incorrectly indexed or unindexed online. Each citation underwent a title screen and a full text review. Eighty-six additional citations were identified for inclusion in the review through this process. Additionally, the research team e-mailed a complete list of citations to key informants to identify unpublished or unindexed literature for inclusion. No additional documents were added, as they had already been identified or did not meet inclusion criteria (e.g., peer-reviewed literature). 


\section{Stage 4: Charting the data}

Results that met inclusion criteria were charted and organized using Microsoft Excel 2010 software, under the following categories: general information; program or service information; evaluation information, including methods, tools, approaches, or frameworks; and principles for research or evaluation. A second reviewer independently charted $20 \%$ of the results and compared them with the first reviewer to ensure that information captured was relevant and sufficiently comprehensive to answer the research question.

\section{Stage 5: Collating, summarizing, and reporting the results}

Descriptive analyses were conducted using Microsoft Excel 2010 to determine the frequencies at which the principles, approaches, methods, tools, or frameworks appeared in the grey literature, and to characterize the origin, type, and date of publication. Cross-tabulations were used to illustrate the frequency at which principles appeared in results classified as guidance or application documents. Findings were used to develop a preliminary report for consultation with key informants.

\section{Stage 6: Consultation}

The objectives of the consultation were to

1. Share preliminary findings of the scoping review with key informants;

2. Identify knowledge gaps (i.e., principles, approaches, methods, tools, and/or frameworks) that were not captured in the scoping review; and

3. Validate and enrich interpretation of preliminary findings.

To achieve these objectives, a qualitative design was utilized. Smylie contacted two existing groups of experts in Indigenous evaluation to request permission for the research team to contact them. Key informants included representatives from local, provincial, and national Indigenous organizations and researchers and evaluators working in Indigenous health. Participants $(N=9)$ had an average of 13 years of experience conducting evaluations with Indigenous communities in the areas of health, health promotion, education, and nursing. Participants were e-mailed a description of the review, a report of the preliminary results, and instructions to provide feedback via an online survey, a semi-structured telephone interview, or a focus group. The consultation included open-ended questions that enabled participants to identify additional documents, as well as experiences and knowledge that might not be available in a written format. Participants were also asked to provide individual verbal or written consent prior to participating. Data from the interviews and focus group were audio recorded and transcribed verbatim, and online survey data were exported from SurveyMonkey into Microsoft Word for further analysis. The consultation component received ethical approval from the Ethics Review Board at PHO. 


\section{Data analysis}

Data were analyzed using a qualitative thematic approach to examine open-ended survey responses, and interview and focus-group transcripts. Two reviewers independently coded two transcripts and compared results to ensure the relevance of the coding to consultation objectives. Themes emerged from the data deductively, whereby categories were created based on predetermined objectives, that is, identifying knowledge gaps, and validating and/or enriching findings, and inductively, as categories arose gradually from the data (Crabtree \& Miller, 1999). New approaches, methods, tools, and frameworks identified during consultation were included in the review if they met the inclusion criteria.

\section{RESULTS}

The grey literature search identified 1,600 search results, of which 124 publicly accessible records met the inclusion criteria. An additional 86 records were identified through snowballing via reference lists. Records included reports, manuals, guidelines, monographs, book chapters, fact sheets, government documents, theses, dissertations, conference proceedings, presentation slides, and bibliographies. After removing records from which no data could be charted (e.g., bibliographies), 185 records were included (see Figure 1).

\section{Record type and origin}

Of the 185 records included in this review, 63\% were classified as guidance documents $(n=116)$, while $37 \%$ were classified as application documents $(n=69)$ (see Figure 2). Records were broadly classified "guidance" if they provided recommendations on how to conduct research or evaluation in an Indigenous context, and "application" if they described research or evaluation executed in an Indigenous context.

Of the 185 records, approximately 52\% $(n=98)$ originated from Canada, $31 \%$ $(n=58)$ from Australia, $8 \%(n=14)$ from New Zealand, and 7\% $(n=13)$ from the United States (see Figure 3$)$. Approximately $61 \%(n=113)$ of the records were released during or after 2010 (see Figure 4). Most records were released in 2012 $(n=25)$, with the fewest in $2001(n=1)$.

\section{Principles}

Of the 185 records, $88 \%(n=162)$ reported one or more principle theme categories for research or evaluation in Indigenous contexts; $13.3 \%$ of results $(n=25)$ described all 15 principle theme categories, and 12.4\% $(n=23)$ described none.

As seen in Table 1, the most frequently cited PTC emphasizes the importance of using community engagement while conducting research or evaluation with Indigenous communities. To better understand how community engagement was used in Indigenous contexts, this theme category was further characterized by the time at which community engagement occurs (i.e., prior to conducting research 


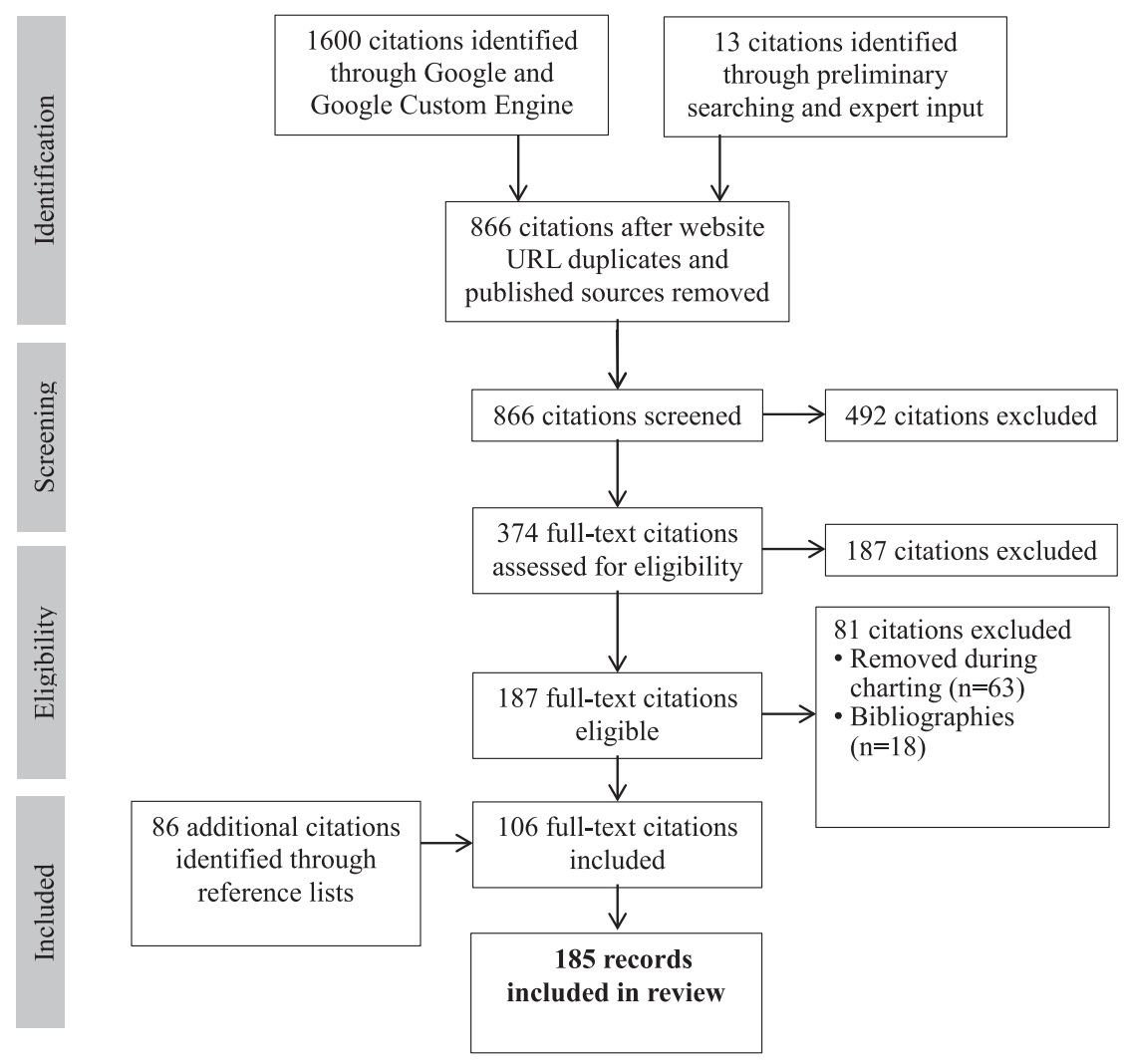

\section{Figure 1. PRISMA flow chart}

[during the planning stages], during research, or after research is completed [during data analysis, and/or knowledge dissemination]). Community engagement prior to research was cited most frequently $(n=130)$, followed by engagement during research $(n=125)$, and engagement after research $(n=118)$. "Research acknowledges power imbalances between Indigenous and non-Indigenous researchers" was least frequently cited $(n=58)(\mathrm{PTC} \# 15)$ within guidance and application documents.

There were 25 records in which all PTCs appeared. All of these were classified as guidance documents (e.g., CIHR et al., 2014; Hudson, Milne, Reynolds, Russell, \& Smith, 2010; Kahnawake Schools Diabetes Prevention Project, 2007; Laycock, Walker, Harrison, \& Brands, 2011). The USAI (Utility, Self-Voicing, Access, and Inter-Relationality framework) Research Framework (Ontario Federation of Indigenous Friendship Centres, 2012), identified through our consultation, also demonstrates all 15 PTCs. Principle theme categories were generally less likely to appear in application documents (see Figure 5), and there were no application documents in which all fifteen PTCs appeared. 


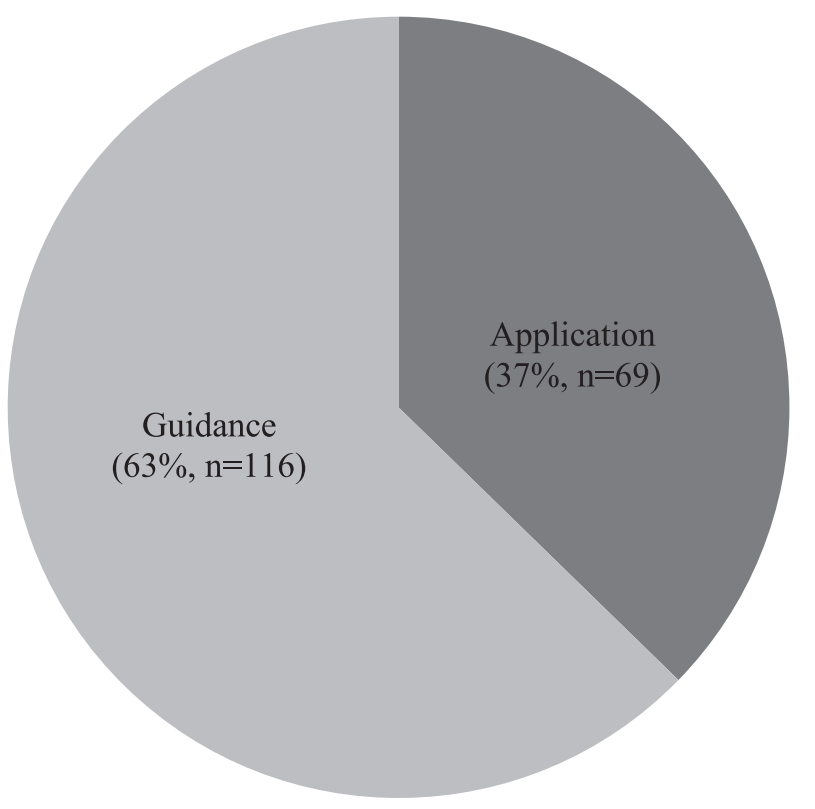

Figure 2. Classification of records, by type

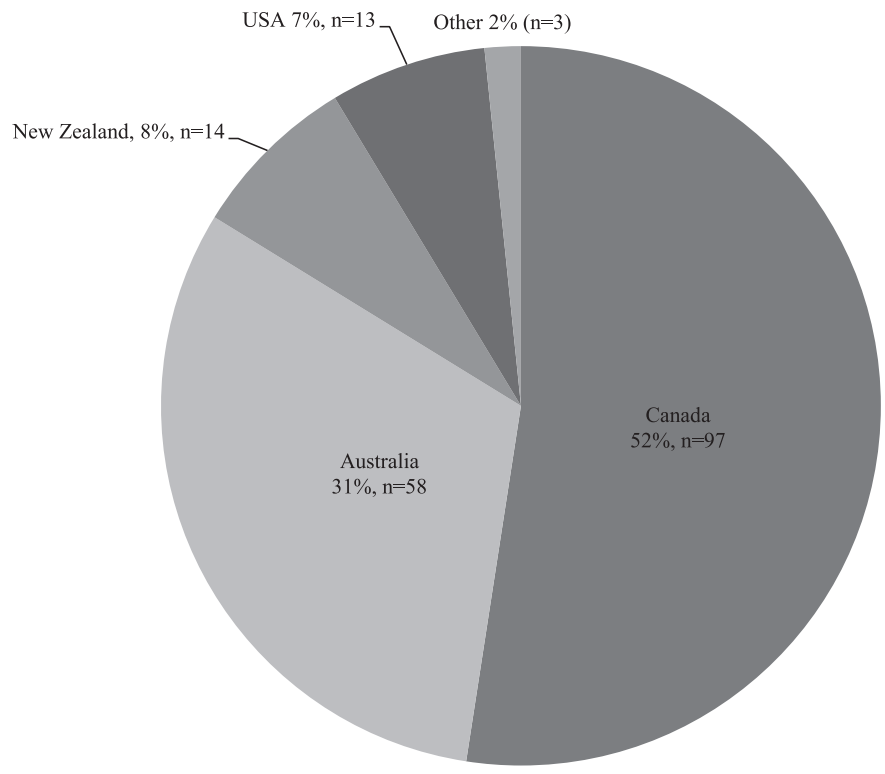

Figure 3. Classification of records, by country of origin 


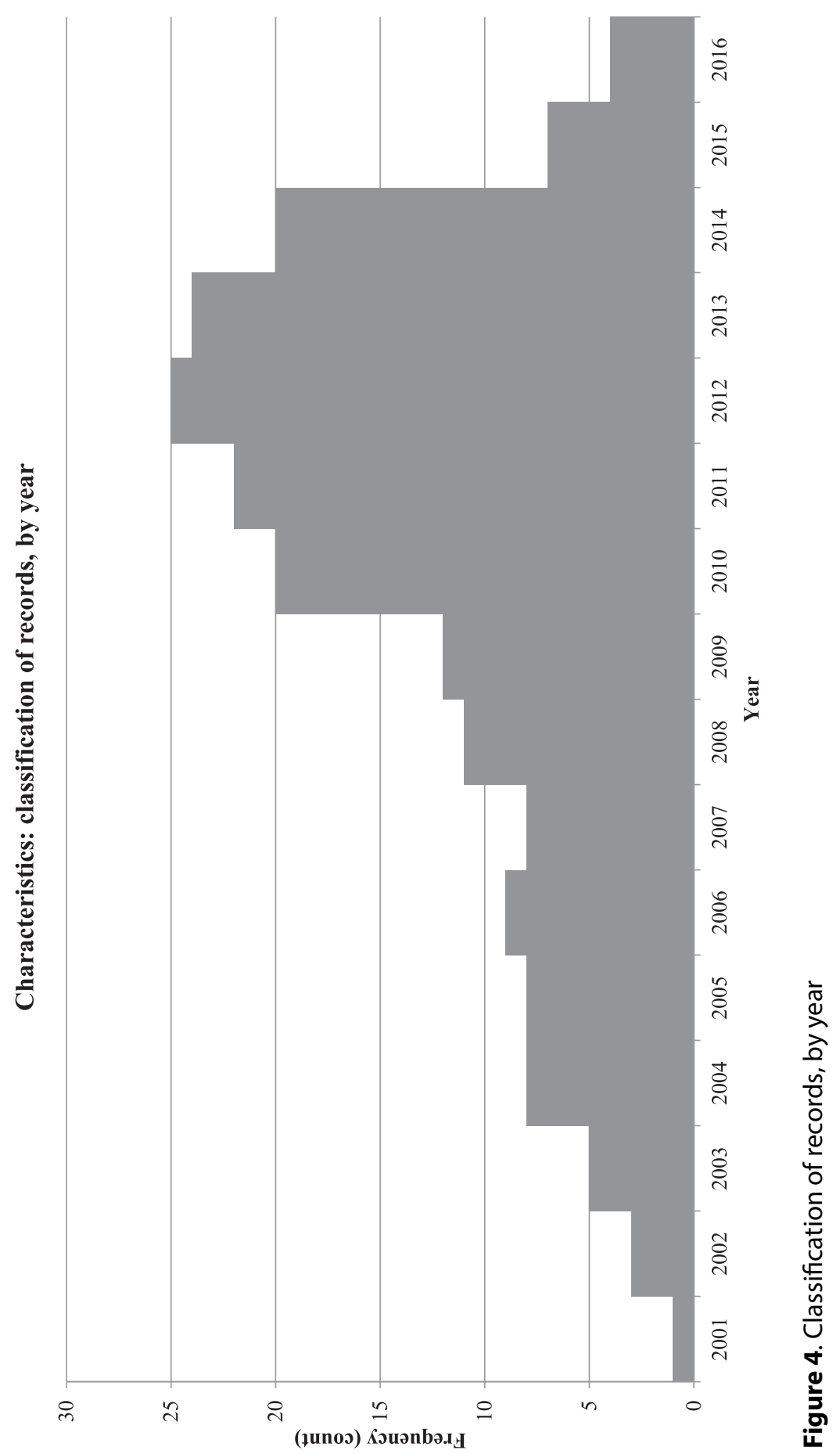


2

3

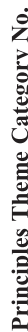

9

11

12

13

14

15

Recognizes power imbalances

0

Culturally appropriate and safe

Specific to the community's context

Respect for participants

Facilitates local capacity building

Benefits are greater than risks

Respect for Indigenous knowledge

Reciprocity for participants

Approved by ethics committee

Uses community engagement

Demonstrates core values, such as honesty

Relevant and responsive to community needs

Guided by community self-determination

Grounded in Indigenous ways of knowing

Community plays role in data governance

$\begin{array}{llllrrrr} & 20 & 40 & 60 & 80 & 100 & 120 & 140\end{array}$

Frequency (count)

घuidance Application

Figure 5. Frequency of principle theme categories, stratified by type of document

\section{Consultation}

Consultation revealed that these principles correctly capture and are "consistent with how ... evaluation should be conducted, but not how it necessarily is conducted [in Indigenous contexts]" (ID_6). ${ }^{3}$ Participants recognized that adhering to the principles may be challenging due to the time it takes for researchers and communities to build trusting relationships, limited funding, adhering to funding deadlines, and limited time available to strengthen community capacity (ID_1b, ID_6). In addition, one expert noted the importance of applying rigour, accuracy, reproducibility, and transparency in reporting the way in which evaluation in 
Indigenous contexts is conducted, and "transparency in reporting how things go with communities" (ID_2).

One participant noted the importance of evaluators developing an understanding of how to operationalize these principles, particularly if they are nonIndigenous:

there's a lot of non-Indigenous researchers that think they're doing good work and are really striving to do good work but just don't have the knowledge of how to do that good work .... So, when we think about, you know, demonstrating reciprocity [PTC\#12] ... a non-Indigenous researcher may think that means, oh, okay I'll just give a gift-card. But, I think for a lot of our Indigenous communities and our Indigenous participants it would mean a lot more than that. It means that I may see you again in three years from now, even when the research is not there. (ID_1b)

\section{Approaches}

An approach was broadly defined as "an integrated set of options used to do some or all of the tasks involved in the evaluation" (Better Evaluation, 2012). Seventy-three percent $(n=135)$ of results used or described using one or more approaches for conducting evaluation in Indigenous contexts. Approaches fell into the following broad categories: participatory approaches or partnerships $(n=99)$, community-based research $(n=32)$, Indigenous-led approaches (e.g., Kaupapa Māori approach) $(n=14)$, strengths-based or strengths-focused approaches $(n=13)$, outcomes-based approaches $(n=5)$, developmental approaches $(n=3)$, empowerment approaches $(n=2)$, and others. Additional approaches identified through consultation were the rights-based approach and the two-eyed seeing approach (see Hovey, Delormier, McComber, Lévesque, \& Martin, 2017; Lavallée \& Lévesque, 2013).

\section{Consultation}

Key informants agreed that the list of approaches was comprehensive but noted several caveats. First, consultation revealed that any approach may be used if that approach is selected as a result of adherence to principles established in partnership with the community. One participant stated, "as long as you let your principles always lead you, I think any of them [the approaches] would work" (ID_1a). Second, another participant noted that although participatory and community-based approaches were most frequently cited, this may lead to "an unhelpful distinction between researchers that are working in communities and researchers that are perhaps using secondary data ... [but] both are completely legitimate. One is not ethically inferior to the other. It just depends on the context and the answers that you're trying to get.” (ID_2). The participant also suggested that the principles established by the community guide what is defined as meaningful community engagement in that evaluation context. Third, one participant cautioned that "although Indigenous approaches can complement communitybased research efforts ... both are distinct and you need to think about how you can integrate both" (ID_1b). In other words, although "community-based 
approaches" may be community informed, they may not necessarily be classified as "Indigenous-led approaches."

\section{Methods for evaluation}

Methods were defined as standardized processes or steps that facilitate access to and use of information (adapted from Robeson, 2009). In this way, 56\% ( $n=104)$ of results described one or more methods for data collection. A majority of results ( $88 \%$, or 92 of 104) that mentioned methods for data collection also used or described using mixed methods (any combination of qualitative and qualitative methods).

Methods included: interviews $(n=81)$, surveys or questionnaires $(n=60)$, program document and program data reviews $(n=48)$, focus groups $(n=46)$, secondary analysis $(n=32)$, literature reviews $(n=28)$, storytelling $(n=18)$, visual or digital storytelling $(n=15)$, site visits or field work $(n=14)$, observation ( $n=14)$, talking or sharing circles $(n=8)$, direct assessments $(n=7)$, life stories ( $n=6$ ), patient journey mapping $(n=4)$, and concept mapping $(n=2)$. Additional methods identified through consultation included Anishnaabe Symbol-based reflection (see Lavallée, 2009), storyboards (see Johnston Research Inc., 2015), dream and poem analysis, and learning circles.

\section{Consultation}

Key informants agreed that the list of methods for conducting evaluation in Indigenous contexts identified through this scoping review was comprehensive. However, they recommended that evaluators be cautious when using "observation" as a method. One participant noted:

sometimes you don't understand what you're observing ... you might not have the context of what's happening or the back story of why it's happening. And, if you walk in at any point in time without [understanding the context] ... it could give a lot of murky data. (ID_1a)

\section{Tools}

Broadly defined, tools were "standardized products such as instruments, surveys and checklists that facilitate access to and use of information" in Indigenous health-service or health-program evaluation (National Collaborating Centre for Methods and Tools, 2017). By this definition, any tools not adaptable to other studies were excluded. Two tools were identified: the Waawiyeyaa Evaluation Tool (Johnston Research Inc., 2015), and the First Nations Regional Health Survey (FNIGC, 2015).

The Waawiyeyaa Evaluation tool, developed in Canada, is a "wholistic [sic] evaluation tool, grounded in Anishnawbe traditional knowledge" (Johnston Research Inc., 2015). This tool enables the collection of culture-based data through a paper-and-pencil crayon storytelling exercise, and uses the Teaching of Self, and the Teaching of the Tree of Life. This tool allows evaluators to document program processes and outcomes (Johnston Research Inc., 2015). 
The First Nations Regional Health Survey is a national longitudinal survey, governed by the First Nations Information Governance Centre (FNIGC) in Canada (FNIGC, 2015). Based on both Western and Indigenous understandings of health and wellness (FNIGC, 2015), it addresses various health indicators, including health status and the determinants of health (Gray, Gideon, Tournier, \& Schnarch, 2004). The survey was validated by First Nations stakeholders and other experts, to address culturally relevant and holistic First Nations priorities (Gray et al., 2004).

\section{Consultation}

Key informants identified six additional tools for data collection, with one meeting the inclusion criteria: the Aboriginal Children's Health and Well-being Measure (ACHWM). Based on the medicine wheel, the ACHWM is a tablet-based survey that allows communities to collect child and youth health data (see Young et al., 2013). The remaining tools were excluded as they did not focus on Indigenous communities (Statistics Canada, 2016), did not refer to a health program or service (Statistics Canada, 2017a, 2017b), did not focus on evaluation practice (Smylie, Firestone, et al., 2011), or were not yet released.

\section{Frameworks}

A framework was broadly defined as "a [standardized] visual or written product that explains, either graphically or in narrative form, the main things to be studied-the key factors, concepts, or variables-and the presumed relationships among them" (Miles \& Huberman, 1994, p. 18). Nine frameworks were identified: seven different frameworks based on the medicine wheel; Visual Maps (see Rutman, Poole, Hume, Hubberstey, \& Van Bibber, 2014); and, the Community Health Indicators Toolkit (Jeffery et al., 2006).

\section{Frameworks based on the medicine wheel}

While components can vary by cultural and community context, the medicine wheel usually consists of four quadrants and might include multiple layers. In our results, the four quadrants often represented mental, spiritual, physical, and emotional health. The four quadrants were used in evaluation contexts to organize indicators of health and well-being, or to help communicate whether a program or service was adequately addressing an issue (Atlantic Council for International Cooperation, 2007; Dapice, 2006).

\section{Visual maps}

Originally developed to map the evaluation of Fetal Alcohol Spectrum Disorder (FASD) programs in British Columbia (Poole, Rutman, Van Bibber, Hummerstey, \& Hume, 2014), visual maps provide a framework for conceptualizing a program's theoretical foundations and community and systemic outcomes. Maps for evaluation of FASD programs in Indigenous communities depicted concentric rings and circular design and were informed by Indigenous understandings of well-being, including holistic approaches to healing and the inter-connectedness of life. These 
maps also emphasized the importance of one's extended family and culture as it relates to wellness (Poole et al., 2014).

\section{Community Health Indicators Toolkit}

This "evaluative framework manual" (Jeffery et al., 2006), developed for use by First Nations health organizations, used a participatory research design with nine Indigenous communities in Saskatchewan to identify culturally relevant and appropriate indicators to measure community health and wellness. The manual contains

1. six health domains or "key factors affecting the health and wellness of a community" (Jeffery et al., 2006, p. 2);

2. indicator categories, or "specific areas [of measurement] within each domain, identified as playing a role in community health and wellness" and its associated issues (p. 2); and

3. suggestions for community-level data sources that "identify the source of the specific question, measure, or existing data that is listed in the indicator table" (p. 3).

\section{Consultation}

Participants agreed that the list of frameworks fit the definition selected for this review. However, participants noted that researchers and evaluators sometimes misuse the medicine wheel to conveniently "Indigenize" research or evaluation: "they think that, if they're going to make it Indigenous they turn it into a medicine wheel" (ID_1a) and that the medicine wheel "conveniently allows the researcher to compartmentalize [indicators] ... into one of those four quadrants" (ID_1b). Furthermore, participants cautioned that each community conceptualizes or understands the medicine wheel in a unique way and that it is not necessarily meaningful to all Indigenous communities in Canada. As a result, participants suggested that communities and evaluators designing a framework based on the medicine wheel need to do so in consultation with, and in a way that adequately represents the views of, the community.

Key informants identified three additional frameworks, and one met the inclusion criteria: the Thunderbird Partnership Mental Health Continuum Framework (see Health Canada, 2015). This framework was developed by the Assembly of First Nations, Health Canada's First Nations and Inuit Health Branch, and Indigenous leaders from various First Nations. Drawing from the medicine wheel, this framework outlines a continuum of mental wellness services characterized by ten rings, including four wellness outcomes, community relationships, population characteristics, population needs, partnerships, and Indigenous social determinants of health. The remaining frameworks were excluded as they did not meet the inclusion criteria, or not enough information was available to classify them (see Aboriginal Family and Community Literacy Curriculum, 2011; Canadian Parks and Recreation Association, 2000; Hart-Wasekeesikaw, 2009). 


\section{DISCUSSION}

This scoping review provides an overview of principles, approaches, methods, tools, and frameworks for evaluation in Indigenous contexts most frequently cited in grey literature from 2000-2015 in Canada, the United States, Australia, and New Zealand. Results suggest several implications for evaluation practice.

First, findings reveal the critical importance of principles guiding evaluation in Indigenous contexts. Principles can be used as a starting point for evaluators and communities to initiate discussion about their evaluation, as well as the most contextually appropriate approaches, methods, tools, or frameworks. As our participants noted, "The community that you want to research [should know about this work] ... then community members can know what their rights are and what they should be expecting from researchers in the process" (ID_1a). For community organizations, a participant noted that the findings might be useful for "creating expectations for staff in terms of what they are ensuring they have in place before they engage in newer community development projects, capacity building within different organizations or community groups, or their own program evaluations" (ID_1c). However, it is important to note that this review does not report best practices, nor does it represent a comprehensive list of approaches, methods, tools, or frameworks from which an evaluator may simply choose, without consideration to principles. This review does not rank or prioritize principles, approaches, methods, tools, or frameworks, except in terms of the frequency in which they appeared. Nevertheless, principles identified through this review are consistent with the United Nations Declaration on the Rights of Indigenous Peoples (2008), the Truth and Reconciliation Commission Calls to Action (2015), and peer-reviewed literature. Specifically, literature indicates that research and/ or evaluation with Indigenous communities should be grounded in Indigenous ways of knowing and traditional Indigenous knowledge (Castellano, 2004; Kovach, 2010), rooted in the community's context, observing community protocols (Grover, 2010; LaFrance, Nichols, \& Kirkhart, 2012; Wilson, 2008), and relevant to and reflective of community needs (PHAC, 2015). Scholars have also identified that researcher-community relationships must exemplify respect and reciprocity (Wilson, 2008), research should benefit communities and support local capacity (Ball \& Janyst, 2008), and communities should have access to evaluation data and results (PHAC, 2015; Riddell, Salamanca, Pepler, Cardinal, \& McIvor, 2017). Further, researchers have highlighted the importance of acknowledging and relinquishing power imbalances (LaFrance, 2004), building strong relationships with communities (Flicker \& Worthington, 2012), seeking guidance from knowledge keepers and elders (George et al., 2007), and engaging the community at the outset of evaluation (Grover, 2010). Finally, the literature indicates that Indigenous peoples have a right to participate in research that affects their well-being (Castellano, 2004; United Nations, 2008) and to exercise community self-determination (First Nations Centre, 2007). The principle theme categories also align with instances in which principles are grouped together. For example, the OCAP principles (Ownership, Control, Access, and Possession) represent principles related to the 
governance and management of health information among Canadian First Nations peoples (First Nations Centre, 2007). These align with PTC \#13: "Indigenous communities have a role with respect to data governance and management" and PTC \#8: "The research is guided by community self-determination" among others. The Treaty of Waitangi principles of protection, participation, and partnership were often cited together in New Zealand Maori research contexts (Hudson et al., 2010). These principles map onto PTC \#1: "Research with Indigenous community uses principles of community engagement" and PTC \#7: "Research partnerships/ collaborations help to facilitate local capacity building." Consultation results indicate that these principles identified through this review are applicable to evaluation in Canadian Indigenous contexts and support an ongoing need for evaluation in these contexts to be conducted according to the identified principles as well as to existing ethical guidelines.

Additionally, findings suggest that despite identification of these principles, there continue to be externally imposed challenges affecting application in realworld evaluation. Consistent with the literature, these include limited time to develop trusting relationships (LaFrance, 2004; Riddell et al., 2017); resource limitations (Chouinard \& Cousins, 2007), and incongruence between funder and community expectations (Cochran et al., 2008). Findings point to a need for evaluators to work with their partner community to identify ways to overcome these challenges and bridge the inconsistencies between theory and practice (Katz, Newton, Bates, \& Raven, 2016).

Second, principles of community engagement indicate that partner communities should be engaged "from the earliest stages of conception and design of projects through to the analysis and dissemination of results" (CIHR et al., 2014, p. 106). Therefore, although interviews, surveys, and focus groups were among the most frequently cited, our findings suggest that any method may be used. Consistent with the literature, methods are determined by evaluation question(s) (Elliott, 1999), informed by the community, and relevant to the community context (Drawson, Toombs, \& Mushquash, 2017). This includes new and emerging methods that may not be highly cited in the literature, including PhotoVoice and digital storytelling (Drawson et al., 2017).

Third, although participatory and community-based approaches were most frequently cited, consultation results suggest that evaluators should be cautious of the distinction between drawing on principles of community engagement and utilizing community-based approaches or methods. Simply stated, not all evaluations that engage communities will use formal community-based participatory research methods or participatory action research methods. Further, consultation results indicate that principles often guide the approach selected for evaluation. We captured a diversity of approaches through this review, which may reflect either the wide range of approaches that have been used for undertaking evaluation in Indigenous contexts or our broad definition of the term "evaluation approach," which lent itself to the purpose of scoping reviews (Arksey \& O’Malley, 2005). 
In contrast, our definitions of tools and frameworks may have been too narrow, as these required that the tools or frameworks identified be "standardized." Standardization in Indigenous contexts may be considered counterintuitive or contentious, as it implies that a tool or framework applies to all evaluations in Indigenous contexts (PHAC, 2015). However, this definition was chosen given that cataloging and obtaining copies of all tools (e.g., unique interview guides) and frameworks developed for Indigenous programs was outside the study scope and may not be included as part of the literature. Rather, the identified tools and frameworks may be adapted by communities and evaluators for their programs. Similarly, the principles, tools, and frameworks identified in this review may provide a useful starting point for communities and evaluators to determine which, if any, to adopt for their evaluation. Future research may consider using different definitions or pre-defined categories to align with current evaluation practice, or further analyzing the content of tools and frameworks for program evaluation in Indigenous contexts.

\section{Strengths}

First, a systematic search and snowballing of reference lists was used to identify a breadth of grey literature. Second, screening was optimized by independent coding of five exemplar articles provided by Smylie, followed by discussion and consensus to sensitize screeners to implicit principles and to identify emergent PTCs. Third, our consultation with Indigenous health key informants at two stages helped identify themes that did not emerge through the literature, which validated and enriched interpretation of findings. This is consistent with PTC \#1: "Research with Indigenous communities uses community engagement." The inclusion of open-ended questions in the consultation elicited participant insights into the practical challenges of conducting evaluation in Indigenous contexts, and strategies for mitigating them, which were particularly valuable. Fourth, aligning the principles with Chapter 9 of TCPS II (CIHR et al., 2014) validated the principle theme categories that emerged from the five exemplar articles. In addition, a new PTC was identified: "Researcher demonstrates core values such as trust, inclusion, transparency, honesty, and integrity." This concept appeared implicitly, but was not explicitly stated throughout Chapter 9 of TCPS II (CIHR et al., 2014). This finding may contribute to literature related to processes for conducting meaningful evaluation with Indigenous communities.

\section{Limitations}

First, a key limitation of this review may be the use of scoping review methodology itself. Although the chosen methodology aligned with the authors' objectives, the methodology was inherently limited in that it was based on Western methods for screening, sorting, and summarizing knowledge on a particular topic. Indeed, the process of breaking down knowledge in this way may be antithetical to holistic and integrated Indigenous perspectives. Further, while the authors made efforts to include and maximize Indigenous voice throughout the scoping review, 
consultation participants noted that a better approach may have been to rely on Indigenous voices from the earliest stages of the scoping review:

I think next time, from the beginning, even though I know there were a lot of Indigenous individuals as part of this project, but [it is important] to really be involving community members and these kind of, key stakeholders, in communities from the get-go. Because, I think that if we took these principle theme codes from the beginning, it could have been written very differently, from the get-go, before they got to us." (ID_1c)

This aligns well with PTC \#14, which states that research with Indigenous communities should use community engagement at various stages of research projects, including stages before the research project has begun. Further, key informants noted that community engagement at early stages allows for the strengthening of Indigenous voices:

[Otherwise] we're kind of creating this hierarchy around these ... research oriented terminologies having more weight. Therefore, what we use in our communities, need to be translated to that in order to be referenced in these documents. So, even for example, when we talk about our principles-Principle \#10: Research with Indigenous communities is grounded in Indigenous epistemologies (i.e. Indigenous ways of knowing) - we have Indigenous epistemologies, but we could just say, Indigenous ways of knowing. And, I think a lot of our community members would just understand what that meant, instead of just having that as an "i.e.", like, as an example of. (ID_1c)

Within the context of scoping review methodology, this review did not involve quality appraisal or content analysis. The approaches, methods, tools, and frameworks that were extracted were documented as stated, and no assessments were undertaken to determine their technical accuracy. In addition, the types of grey literature included were highly variable. While these results passed a relevance test, a wide range of detail between documents suggests that there may be a discrepancy between what is reported and what occurs in practice. Therefore, there is a need for future research to gain a clearer understanding of the extent to which principles, approaches, methods, tools, and frameworks used for evaluation in Indigenous contexts are being applied.

Additionally, more than half of the literature included in this review was of Canadian origin. Thus, the identified tools and frameworks may be less applicable to non-Canadian Indigenous contexts. This bias likely occurred due to a focus on Canadian websites in the Google Custom search engine. Further research focused on literature emerging from New Zealand, Australia, and the United States is needed. Validation of these findings with an international group of key informants may also be appropriate. Future research may draw from literature focused on the social determinants of health, including housing and employment, given that Indigenous determinants of health and their relationship to health outcomes in Indigenous populations are unique and varied (Mikkonen \& Raphael, 2010). 
Finally, this review did not capture how principles for evaluation may be operationalized in various contexts. Future research to determine how to operationalize the principles, and to identify ways in which to mitigate practical challenges in diverse Indigenous contexts, is warranted (Katz et al., 2016).

\section{CONCLUSION}

Building scholarship regarding approaches, methods, and tools for Indigenous health service and program evaluation requires further research, including documenting local adaptations of specific Indigenous evaluation projects. The guiding principles, approaches, methods, tools, and frameworks identified through this review may be a useful starting point for evaluators and communities to initiate discussion about how to conduct evaluations in their communities.

\section{ACKNOWLEDGEMENTS}

This research was supported by a CIHR Planning and Dissemination Grant (Grant \# CIHR-PCS-142061) and funding from Public Health Ontario. The authors would like to thank the key informants who participated in consultation through an online survey, telephone interviews, or telephone focus groups.

\section{NOTES}

1. Grey literature is "information produced outside of traditional publishing and distribution channels, and can include reports, working papers, newsletters, government documents, speeches, white papers, urban plans, and so on" (Simon Fraser University Library, 2018).

2. In this context, snowball sampling was utilized to identify highly cited literature, "by 'footnote chasing,' which involves searching the citation indices, or by browsing through the list of bibliographies of selected reports on the relevant topic" (Harsh, 2011, p. 68).

3. Participants were assigned identification numbers arbitrarily, in the order in which they expressed interest in participating.

\section{REFERENCES}

Aboriginal Family and Community Literacy Curriculum. (2011). Reading: Circle of courage frameworks - Aboriginal family and community literacy curriculum. Vancouver, BC: University of British Columbia.

Armitage, A. (1995). Comparing the policy of aboriginal assimilation: Australia, Canada, and New Zealand. Vancouver, BC: University of British Columbia Press.

Arksey, H., \& O’Malley, L. (2005). Scoping studies: Towards a methodological framework. International Journal of Social Research Methodology, 8(1), 19-32. https://doi.org/10. 1080/1364557032000119616

Athabasca University. (2015). Aboriginal organizations. Athabasca, AB: Author. Retrieved from http://indigenous.athabascau.ca/resources/library/aboriginal/index.php 
Atlantic Council for International Cooperation. (2007). Medicine wheel evaluation framework. Halifax, NS: Atlantic Council for International Cooperation. Retrieved from http://static1.1.sqspcdn.com/static/f/1590842/20068323/1349103128263/Medicine _ Wheel_Evaluation_Framework.pdf?token=llFfXrrug9OHQlTc5Eff288RuN4\%3D

Ball, J., \& Janyst, P. (2008). Enacting research ethics in partnerships with Indigenous communities in Canada: "Do it in a good way." Journal of Empirical Research on Human Research Ethics, 3(2), 33-51. https://doi.org/10.1525/jer.2008.3.2.33 . Medline: 19385744

Better Evaluation. (2012). Approaches. Melbourne, Australia: RMIT University. Retrieved from http://www.betterevaluation.org/en/approaches

Canadian Institute of Health Research (CIHR), Natural Sciences and Engineering Research Council of Canada (NSERC), and Social Sciences and Humanities Research Council of Canada (SSHRC). (2014). Tri-Council policy statement: Ethical conduct for research involving humans. Ottawa, ON: Government of Canada. Retrieved from http://www. pre.ethics.gc.ca/eng/policy-politique/initiatives/tcps2-eptc2/Default/

Canadian Parks and Recreation Association. (2000). Toolkits: Everybody gets to play community mobilization tool kit. Ottawa, ON: Canadian Parks and Recreation Association.

Castellano, M. B. (2004). Ethics of Aboriginal research. International Journal of Indigenous Health, 1(1), 98. Retrieved from https://www.nvit.ca/docs/ethics\%20of\%20aboriginal\%20research.pdf

Chesterton, P. (2003). Balancing ethical principles in evaluation: A case study. The Canadian Journal of Program Evaluation, 18(1), 49-60.

Chouinard, J. A., \& Cousins, J. B. (2007). Culturally competent evaluation for Aboriginal communities: A review of the empirical literature. Journal of MultiDisciplinary Evaluation, 4(8), 40-57.

Cochran, P. A. L., Marshall, C. A., Garcia-Downing, C., Kendall, E., Cook, D., McCubbin, L., \& Gover, R. M. S. (2008). Indigenous ways of knowing: Implications for participatory research and community. American Journal of Public Health, 98(1), 22-27. https://doi.org/10.2105/AJPH.2006.093641

Crabtree, B. F., \& Miller, W. L. (Eds.). (1999). Doing qualitative research. Newbury Park, CA: SAGE.

Dapice, A. N. (2006). The medicine wheel. Journal of Transcultural Nursing, 17(3), 251-260. https://doi.org/10.1177/1043659606288383

Drawson, A. S., Toombs, E., \& Mushquash, C. J. (2017). Indigenous research methods: A systematic review. International Indigenous Policy Journal, 8(2), 1-27.

Elliott, S. J. (1999). And the question shall determine the method. Professional Geographer, 51(2), 240-243.

First Nations Centre. (2007). OCAP: Ownership, control, access and possession. Ottawa, ON: National Aboriginal Health Organization. Retrieved from http://cahr.uvic.ca/nearbc/ documents/2009/FNC-OCAP.pdf

First Nations Information Governance Centre (FNIGC). (2015). First Nations Regional Health Survey (RHS) 2008/10: National report on adults, youth and children living in First Nations communities. Ottawa, ON: First Nations Information Governance 
Centre. Retrieved from http://fnigc.ca/sites/default/files/docs/first_nations_regional_health_survey_rhs_2008-10_-_national_report.pdf

Flicker, S., \& Worthington, C. A. (2012). Public health research involving Aboriginal Peoples: Research ethics board stakeholders' reflections on ethics principles and research processes. Canadian Journal of Public Health, 103(1), 19-22. https://journal.cpha.ca/ index.php/cjph/article/viewFile/2896/2570. Medline:22338323

George, M. A., Masotti, P., MacLeod, S., Van Bibber, M., Loock, C., Fleming, M., . . . . Smith, C. (2007). Bridging the research gap: Aboriginal and academic collaboration in FASD prevention. The Healthy Communities, Mothers, and Children Project. Aboriginal and academic collaboration in FASD prevention. Alaska Medicine, 49(Suppl. 2), 139-141.

Gray, J., Gideon, V., Tournier, C., \& Schnarch, B. (2004). Our voice, our survey, our future: The "survey of choice" by First Nations in Canada. Proceedings from Workshop on Data Collection and Disaggregation on Indigenous peoples, Permanent Forum on Indigenous Issues, New York, NY.

Greenhalgh, T., \& Peacock, R. (2005). Effectiveness and efficiency of search methods in systematic reviews of complex evidence: Audit of primary sources. British Medical Journal, 331(7524), 1064-1065. https://doi.org/10.1136/bmj.38636.593461.68 . Medline: 16230312

Grover, J. G. (2010). Challenges in applying Indigenous evaluation practices in mainstream grant programs to Indigenous communities. Canadian Journal of Program Evaluation, 23(2), 33-50.

Hart-Wasekeesikaw, F. (2009). Cultural competence and cultural safety in nursing education: A framework for First Nations, Inuit, and Métis nursing. Ottawa, ON: Canadian Indigenous Nurses Association. Retrieved from https://cna-aiic.ca/ /media/cna/ page-content/pdf-en/first_nations_framework_e.pdf

Health Canada. (2015). First Nations mental wellness continuum framework. Ottawa, ON: Author. Retrieved from http://publications.gc.ca/collections/collection_2015/sc-hc/ H34-278-1-2014-eng.pdf

Hovey, R. B., Delormier, T., McComber, A. M., Lévesque, L., \& Martin, D. (2017). Enhancing Indigenous health promotion research through two-eyed seeing: A hermeneutic relational process. Qualitative Health Research, 27(9), 1-10. https://doi. org/10.1177/1049732317697948 . Medline:28682710

Hudson, M., Milne, M., Reynolds, P., Russell, K., \& Smith, B. (2010). Te ara tika: Guidelines for Māori research ethics: A framework for researchers and ethics committee members. Auckland, New Zealand: Health Research Council of New Zealand on behalf of the Putaiora Writing Group. Retrieved from http://www.hrc.govt.nz/sites/default/files/ Te\%20Ara\%20Tika\%20Guidelines\%20for\%20Maori\%20Research\%20Ethics.pdf

Jeffery, B., Abonyi, S., Hamilton, C., Bird, S., Denechezhe, M., Lidguerre, T., ... \& Whitecap, Z. (2006). Community health indicators toolkit. Prince Albert, SK: University of Regina and University of Saskatchewan.

Johnston Research Inc. (2015). Toronto, ON: Author. Retrieved from http://www.johnstonresearch.ca/ 
Kahnawake Schools Diabetes Prevention Project. (2007). Code of research ethics. Kahnawake, QC: Author. Retrieved from http://www.ksdpp.org/media/ksdpp_code_ of_research_ethics2007.pdf

Katz, I., Newton, B. J., Bates, S., \& Raven, M. (2016). Evaluation theories and approaches; Relevance for Aboriginal contexts. Sydney, Australia: Social Policy Research Centre, UNSW Australia.

Kovach, M. E. (2010). Indigenous methodologies: Characteristics, conversations, and contexts. Toronto, ON: University of Toronto Press.

LaFrance, J. (2004). Culturally competent evaluation in Indian country. New Directions for Evaluation, 2004(102), 39-50. https://doi.org/10.1002/ev.114

LaFrance, J., \& Nichols, R. (2008). Reframing evaluation: Defining an Indigenous evaluation framework. Canadian Journal of Program Evaluation, 23(2), 13.

LaFrance, J., Nichols, R., \& Kirkhart, K. E. (2012). Culture writes the script: On the centrality of context in Indigenous evaluation. New Directions for Evaluation, 2012(135), 59-74. https://doi.org/10.1002/ev.20027

Lavallée, L. F. (2009). Practical application of an Indigenous research framework and two qualitative Indigenous research methods: Sharing circles and Anishnaabe symbolbased reflection. International Journal of Qualitative Methods, 8(1), 21-40. https://doi. org/10.1177/160940690900800103

Lavallée, L., \& Lévesque, L. (2013). Two-eyed seeing: Physical activity, sport, and recreation promotion in Indigenous communities. In J. Forsyth \& A. R. Giles (Eds.), Aboriginal peoples and sport in Canada: Historical foundations and contemporary Issues (pp. 206-228). Vancouver, BC: University of British Columbia Press.

Laycock, A., Walker, D., Harrison, N., \& Brands, J. (2011). Researching Indigenous health: A practical guide for researchers. Carlton, Australia: The Lowitja Institute.

Levac, D., Colquhoun, H., \& O’Brien, K. K. (2010). Scoping studies: Advancing the methodology. Implementation Science, 5(1), 69. https://doi.org/10.1186/1748-5908-5-69

Maddox, R., Blais, G., Monchalin, R., Firestone, M., Ziegler, C., Mashford-Pringle, A., \& Smylie, J. (in press). Evaluation of Indigenous health service and program evaluations: A systematic review (Unpublished manuscript). Toronto, ON: Well Living House Action Research Centre.

Mikkonen, J., \& Raphael, D. (2010). Social determinants of health: The Canadian facts. Toronto, ON: York University, School of Health Policy and Management.

Miles, M. B., \& Huberman, A. M. (1994). Conceptual framework. In Qualitative data analysis: An expanded sourcebook (pp. 40-49). Thousand Oaks, CA: SAGE.

National Aboriginal Health Organization. (2003). Winds of change: A strategy for health policy research and analysis. Ottawa, ON: National Aboriginal Health Organization.

National Collaborating Centre for Aboriginal Health. (2013). Indigenous approaches to program evaluation. Prince George, BC: National Collaborating Centre for Aboriginal Health. Retrieved from http:www.nccah-ccnsa.ca/docs/Aboriginal\%20ActNow\%20resources/actnow\%20fact\%20sheets/2337_NCCAH_fs_indigenous_prog_eval_web.pdf

National Collaborating Centre for Methods and Tools. (2017). Glossary. Hamilton, ON: McMaster University. Retrieved from http://www.nccmt.ca/glossary 
Ontario Federation of Indigenous Friendship Centres. (2012). USAI (utility, self-voicing, access, and inter-relationality framework) research framework. Toronto, ON: Ontario Federation of Indigenous Friendship Centres. Retrieved from http://ofifc.org/sites/ default/files/docs/USAI\%20Research\%20Framework\%20Booklet\%202012.pdf

Pham, M. T., Rajić, A., Greig, J. D., Sargeant, J. M., Papadopoulos, A., \& McEwen, S. A. (2014). A scoping review of scoping reviews: Advancing the approach and enhancing the consistency. Research synthesis methods, 5(4), 371-385. https://doi.org/10.1002/ jrsm.1123. Medline:26052958

Poole, N., Rutman, D., Van Bibber, M., Hummerstey, C., \& Hume, S. (2014). Evaluating FASD prevention and support programs: Tools to support planning and evaluation. Vancouver, BC: British Columbia Centre of Excellence for Women's Health. Retrieved from http://www.fasd-evaluation.ca/wp-content/uploads/2012/10/FASD-EvaluationFramework-Webinar-Slides-Feb-25-2014.pdf

Principle. In Oxford English Dictionary. Retrieved from https://en.oxforddictionaries.com/ definition/principle

Public Health Agency of Canada (PHAC). (2015). Ways tried and true: Aboriginal methodological framework for the Canadian best practices initiative. Ottawa, ON: Public Health Agency of Canada. Retrieved from http://publications.gc.ca/collections/ collection_2015/aspc-phac/HP35-59-2015-eng.pdf

Putt, J. (2013). Conducting research with Indigenous people and communities. Canberra City, Australia: Indigenous Justice Clearinghouse. Retrieved from http://www.indigenousjustice.gov.au/briefs/brief015.pdf

Reading, C. L., \& Wien, F. (2009). Health inequalities and social determinants of Aboriginal peoples' health. Prince George, BC: National Collaborating Centre for Aboriginal Health. Retrieved from http://www.nccah-ccnsa.ca/Publications/Lists/Publications/ Attachments/46/health_inequalities_EN_web.pdf

Reading, J. (2009). The crisis of chronic disease among Aboriginal Peoples: A challenge for public health, population health and social policy. Victoria, BC: Centre for Aboriginal Health Research, University of Victoria.

Riddell, J. K., Salamanca, A., Pepler, D. J., Cardinal, S., \& McIvor, O. (2017). Laying the groundwork: A practical guide for ethical research with Indigenous communities. International Indigenous Policy Journal, 8(2), 6. https://doi.org/10.18584/iipj.2017.8.2.6

Robeson, P. (2009). Networking in public health: Exploring the value of networks to the National Collaborating Centres for Public Health. Hamilton, ON: National Collaborating Centre for Methods and Tools. Retrieved from http://www.nccmt.ca/pubs/ NetworkingPaperApr09EN_WEB.pdf

Rossi, P. H., Lipsey, M. W., \& Freeman, H. E. (2003). Evaluation: A systematic approach. Thousand Oaks, CA: SAGE.

Rutman, D., Poole, N., Hume, S., Hubberstey, C., \& Van Bibber, M. (2014). Building a framework for evaluation of fetal alcohol spectrum disorder prevention and support programs: A collaborative Canadian project. International Journal of Alcohol and Drug Research, 3(1), 81-89. https://doi.org/10.7895/ijadr.v3i1.122 
Simon Fraser University Library. (2018). Grey literature: What it is \& how to find it. Vancouver, BC: Simon Fraser University. Retrieved from https://www.lib.sfu.ca/help/ research-assistance/format-type/grey-literature

Smith, L. (1999). Decolonizing methodologies: Research and Indigenous peoples. London, England: Zed Books.

Smylie, J., \& Anderson, M. (2006). Understanding the health of Indigenous peoples in Canada: Key methodological and conceptual challenges. Canadian Medical Association Journal, 175(6), 602. https://doi.org/10.1503/cmaj.060940 . Medline:16966664

Smylie, J., Firestone, M., Cochran, L., Prince, C., Maracle, S., Morley, M., ... \& McPherson, B. (2011). Our health counts: Urban Aboriginal database research project: Community report. Hamilton, ON: Well Living House Action Research Centre.

Smylie, J., Lofters, A., Firestone, M., \& O'Campo, P. (2011). Population-based data and community empowerment. In P. O'Campo \& J. R. Dunn (Eds.), Rethinking social epidemiology: Towards a science of change (pp. 67-92). Dordrecht, Netherlands: Springer Science \& Business Media.

Statistics Canada. (2016). Canadian Community Health Survey-annual component (CCHS). Ottawa, ON: Statistics Canada. Retrieved from http://www23.statcan.gc.ca/ $\mathrm{imdb} / \mathrm{p} 2 \mathrm{SV}$.pl?Function=getSurvey\&SDDS=3226

Statistics Canada. (2017a). Aboriginal peoples survey 2012. Ottawa, ON: Statistics Canada, Indigenous and Northern Affairs Canada. Retrieved from http://www.aadnc-aandc. gc.ca/eng/1321384019753/1322059098232\#2012

Statistics Canada. (2017b). First Nations regional early childhood, education and employment survey. Ottawa, ON: Statistics Canada, Indigenous and Northern Affairs Canada. Retrieved from http://www.aadnc-aandc.gc.ca/eng/1321384019753/132205909 8232\#Enq2012

Suri, H. (2011). Purposeful sampling in qualitative research synthesis. Qualitative Research Journal, 11(2), 63-75.

Taylor, R. (2003). An Indigenous perspective on evaluations in the inter-cultural context: How far can one throw a Moree boomerang? Evaluation Journal of Australasia, 3(2), 44-53. https://doi.org/10.1177/1035719X0300300211

Truth and Reconciliation Commission of Canada. (2015). Honouring the truth, reconciling for the future: Summary report of the final report of the Truth and Reconciliation Commission of Canada. Winnipeg, MB: National Centre for Truth and Reconciliation. Retrieved from http://nctr.ca/assets/reports/Final\%20Reports/ Executive_Summary_English_Web.pdf

United Nations. (2008). United Nations declaration on the rights of Indigenous peoples. Geneva, Switzerland: United Nations. Retrieved from http://www.un.org/esa/socdev/ unpfii/documents/DRIPS_en.pdf

Wilson, S. (2008). Research is ceremony: Indigenous research methods. Blackpoint, NS: Fernwood Publishing.

Young, N. L., Wabano, M. J., Burke, T. A., Ritchie, S. D., Mishibinijima, D., \& Corbiere, R. G. (2013). A process for creating the Aboriginal children's health and well-being measure (ACHWM). Canadian Journal of Public Health, 104(2), 136-141. https://journal.cpha. ca/index.php/cjph/article/view/3636. Medline:23618206 
Zorzi, R., Perrin, B., Mcguire, M., Long, B., \& Lee, L. (2002). Defining the benefits, outputs, and knowledge elements of program evaluation. Canadian Journal of Program Evaluation, 17(3), 143-150.

\section{AUTHOR INFORMATION}

Kriti Chandna was a research assistant at Public Health Ontario during the writing of this manuscript. She is currently a Health Promotion and Research Analyst at the Region of Waterloo Public Health. Her research interests include program evaluation, health promotion, and Indigenous health.

Michelle M. Vine is an Evaluation Specialist at Public Health Ontario and holds an adjunct appointment at the University of Waterloo. She is currently working to complete the Credentialed Evaluator designation from the Canadian Evaluation Society. Her research interests include healthy policy, public health program evaluation, school nutrition policy, children and youth and qualitative methods.

Susan J. Snelling is an Evaluation Specialist at Public Health Ontario and holds a Credentialed Evaluator designation from the Canadian Evaluation Society. She is of Métis ancestry and holds an adjunct appointment at Laurentian University. Her research focuses on program evaluation and the use of evidence-informed practices in public and population health, particularly with respect to Indigenous health and rural and Northern health.

Rachel Harris is a Research Facilitator at Public Health Ontario. Her interests include community-based participatory research, arts-based and qualitative research methods, health equity, and decolonizing public health.

Janet Smylie is a respected international leader in the field of Indigenous health and one of Canada’s first Métis physicians. Her 25-year career has been focused on addressing inequities in the health of Indigenous peoples in Canada by bridging gaps in health knowledge and practice. She currently holds a Canadian Institutes of Health Research Applied Public Health Research Chair in Indigenous Health Knowledge and Information at St. Michael's Hospital, where she directs the Well Living House Action Research Centre for Indigenous Infant, Child and Family Health and Wellbeing and is an active staff physician.

Heather Manson is Chief of Health Promotion, Chronic Disease and Injury Prevention at Public Health Ontario. She has over eight years of experience in public health research and evaluation, and extensive clinical, public health and health system leadership experience. She is an assistant professor at the University of Toronto (status only) and the University of Waterloo, and a fellow of the Royal College of Physicians and Surgeons. She is principal investigator on a project to describe neighbourhood walkability in Canada to investigate its association with physical activity and obesity, a CIHR-funded dissemination grant to report on the burden of mental illness and addictions in Canada, and a province-wide process evaluation of the Healthy Babies, Healthy Children Program in Ontario. 